\title{
The potential for vaccination in leprosy elimination: new tools for targeted interventions
}

\author{
Malcolm S Duthie ${ }^{1 /+}$, Paul Saunderson ${ }^{2,3}$, Steven G Reed ${ }^{1}$ \\ ${ }^{1}$ Infectious Disease Research Institute, Seattle, WA, USA ²American Leprosy Missions, Greenville, SC, USA \\ ${ }^{3}$ Leonard Wood Memorial Center for Leprosy Research, Cebu, Philippines
}

\begin{abstract}
Despite the huge effort and massive advances toward the elimination of leprosy over the last two decades, the disease has proven stubborn; new case detection rates have stabilised over the last few years and leprosy remains endemic in a number of localised regions. The American Leprosy Missions and Infectious Disease Research Institute have undertaken a large research effort aimed at developing new tools and a vaccine to continue the push for leprosy elimination. In this paper, we outline our strategy for the integration of rapid diagnostic tests and lab-based assays to facilitate the detection of early or asymptomatic leprosy cases, as well as the efficient and focused implementation of chemoprophylaxis and immunisation to intervene in leprosy development and transmission.
\end{abstract}

Key words: mycobacteria - diagnosis - chemoprophylaxis - vaccine - antibody - T-cell

According to the statistics, the World Health Organization (WHO)-directed leprosy elimination program based upon the provision of multi-drug therapy (MDT) was a major success. Leprosy was targeted for a reduction in prevalence to less than one case per 10,000 people by the year 2000 and $90 \%$ of the countries where leprosy was considered to be a public health problem reported numbers below this threshold (WHO 2005). Worldwide, a 98\% reduction (12 million to less than 0.25 million) in active cases was achieved between 1991-2006 (WHO 2007).

By removing a major source of transmission (person to person), it was believed that these dramatic reductions would allow the downward trend to continue beyond the elimination goal. Since 2000, the worldwide rate of new case detection for leprosy has, however, remained stable at approximately 250,000 new cases each year (Meima et al. 2004a, Lockwood \& Suneetha 2005, WHO 2005, 2007). In some countries, these rates are actually increasing and localised regions with high endemicity remain (Lockwood 2002, Penna et al. 2009, WHO 2010). Leprosy is a slow-onset disease, as the time from infection to symptom emergence is estimated to be, on average, seven years. Given the stability of case reporting over the last decade, we now appear to have moved beyond the timeframe in which residual effects on patient/ contact transmission would be observed. Indeed, mathematical modelling suggests that the disease will remain a major public health problem for at least several more decades (Meima et al. 2004a).

Financial support: ALM, The Heiser Program for Research in Leprosy and Tuberculosis/NYCT, NIH, Renaissance Health Service Corporation + Corresponding author: mduthie@idri.org

Received 20 March 2012

Accepted 17 July 2012
The WHO directive for 2011-2015 outlined a strategy of early detection and treatment to retain leprosy control (Pannikar 2009). This consistent message indicates that continuing earlier treatment will interrupt transmission, reduce the number of new cases and facilitate elimination. The implementation of rigorous case detection to provide early detection is, however, problematic. Without the development of improved monitoring strategies, therapies and interventions, further reduction of leprosy cases seems unlikely.

\section{MATERIALS AND METHODS}

Infectious Disease Research Institute (IDRI)/American Leprosy Missions (ALM) leprosy eradication campaign - Over the last decade, the ALM and the IDRI have embarked on an ambitious research program to develop new tools to aid in leprosy control efforts. The ultimate goal of this program is to provide a vaccine to prevent leprosy, but we also recognise a need for diagnostic screening to permit targeted interventions to assist in the control of the disease. Thus, our strategy centres on three key developments: (i) validating and implementing tests that can identify leprosy patients and asymptomatic Mycobacterium leprae-infected individuals (permitting detection prior to the emergence of clinical signs), (ii) providing post-exposure prophylaxis through intervention measures in asymptomatic individuals and at-risk populations (short-term protection by chemoprophylaxis accompanied by long-term vaccine-induced protection) and (iii) integrating preventative measures with diagnostic tests (allowing targeted and efficient intervention).

Stage 1 - Diagnosis - There is currently no single, widely used diagnostic laboratory test for leprosy and diagnosis continues to be based most frequently on clinical assessments. Clinical diagnosis of leprosy is dependent upon the recognition of disease signs and symptoms and is therefore only possible once the disease has become manifest. WHO experts have listed diagnostic criteria as one or more of the following: hypo-pigmented 
or reddish skin patches with definite loss of sensation, thickened peripheral nerves with loss of sensation and acid-fast bacilli on skin smears/biopsies (WHO 1998). The clinical system suggested by the WHO then uses the number of skin lesions and number of involved nerves to group leprosy patients into one of two simplified categories: multibacillary (MB) leprosy (more than 5 lesions) and paucibacillary (PB) leprosy (up to 5 lesions).

A short detection delay is key to the success of the current MDT-based leprosy control strategy (Meima et al. 2004b), although epidemiological and clinical evidence suggest that current detection times are unacceptably long. The success of prior efforts has led to many countries integrating specialised leprosy control personnel into routine health service systems. In situations with limited resources, this should be acknowledged as an inevitable (and acceptable) outcome. From the viewpoint of leprosy control, however, this means that fewer individuals are capable of confidently diagnosing and treating the disease at the primary point of care (Pandey \& Rathod 2010). In addition, the likelihood that clinical diagnosis is delayed or even missed, especially in regions where leprosy has been "controlled", has increased (Van Buynder et al. 1999, Lockwood \& Reid 2001, Anderson et al. 2007, Flower et al. 2007, Shen et al. 2010). Even in countries reporting large numbers of patients, diagnosis is delayed. For example, the frequency of MB forms and cases within family members indicates delayed diagnoses in the state of Maranhão (MA), Brazil (Correa et al. 2012). A policy of "new case validation" in the state of Orissa, India, in which MDT was not initiated until the initial diagnosis by a primary health care provider was verified by a leprosy expert, may have led to approxi- mately one-quarter of suspected cases waiting one-eight months for confirmation of their diagnosis (Siddiqui et al. 2009). In many cases, leprosy patients are only registered when irreversible nerve damage has already occurred and these individuals have a much greater risk of developing further and more severe nerve impairment (Croft et al. 2000, Nicholls et al. 2003). Thus, the goal of identifying subclinical $M$. leprae infections/asymptomatic individuals before the emergence of fulminant leprosy appears to be beyond the scope of current control measures.

Simple and objective tests to detect infection would not only alleviate the pressure on clinicians to recognise very early signs of leprosy, but could provide the possibility of detecting infection before any clinical signs can be distinguished. Rapid diagnostic tests (RDT) based on antibody responses to the M. leprae phenolic glycolipid (PGL)-I, which are effective for detecting infection in MB patients, have been created (Cho et al. 1983, Young \& Buchanan 1983, Roche et al. 1990, 1999, Buhrer et al. 1998, Oskam et al. 2003, Bührer-Sékula et al. 2003). Commercial availability of such tests has, however, been restricted. The Leprosy SD test (Standard Diagnostics, Seoul, South Korea) is a single lateral flow test based on the detection of antibodies to PGL-I in plasma, but it is no longer listed in the Standard Diagnostics catalogue. The ML flow test (KIT Biomedical Research, Royal Tropical Institute, Amsterdam, Netherlands) was developed to analyse blood and serum samples; however, this test has not been widely implemented in field situations and has mainly been used in support of clinical examination as a means to direct the treatment of $\mathrm{PB}$ and $\mathrm{MB}$ patients (Bührer-Sékula et al. 2003, 2009, Oskam et al. 2003, Contin et al. 2011).
A

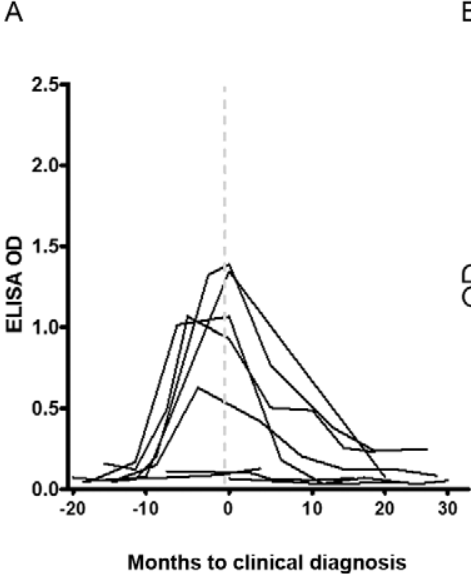

B

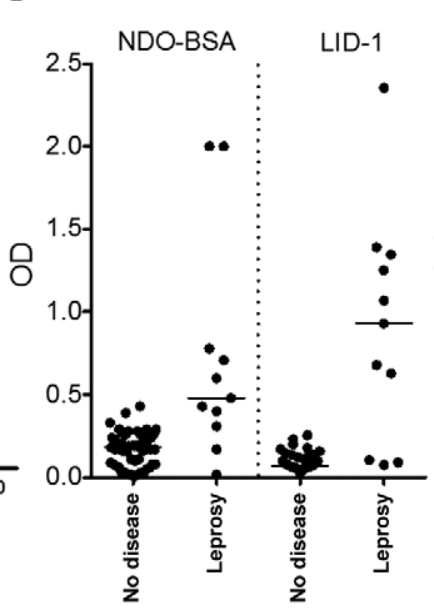

C

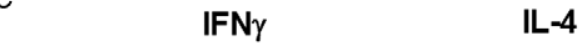

Fig. 1: predictive values of serological and cellular assays. A: the anti-Leprosy Infectious Disease Research Institute Diagnostic (LID)-1 antibody responses of contacts who developed multibacillary (MB) leprosy during the course of a five year surveillance study in the Philippines were monitored over time and contrasted against the time at which clinical diagnosis was achieved [both datasets were first reported in Duthie et al. (2007)]; B: from the same study, the antibody responses against natural disaccharide octyl-bovine serum albumin (NDO-BSA) and LID-1 of healthy household contacts (HHC) that either did or did not develop leprosy [reported in Duthie et al. (2007)]; C: the differential antigenspecific cytokine response of MB, paucibacillary (PB) and HHC are shown [1st reported in Sampaio et al. (2011a)]. Blood was incubated with recombinant ML0405 protein and cytokines secreted into the plasma analyzed. PB patients responded by secreting IFN- $\gamma$ and MB patients responded by secreting interleukin (IL)-4, while the majority of HHC demonstrated a PB-like profile; one HHC, however, responded similarly to MB patients and therefore may not be protected against Mycobacterium leprae replication; OD: optical density. 


\section{RESULTS}

Our diagnostic strategy - Stage 1 of our campaign will evaluate the performance of both lab-based tests and RDT, which we are currently developing and establish if strong responses to the Leprosy IDRI Diagnostic (LID)-1 protein are predictive of advancement to leprosy (Fig. 1A, B). The introduction of a simple serological surveillance program will provide an objective measurement that can be made by non-specialised personnel and be used to provide referrals or instruction to clinicians.

Contact tracing has been suggested as a major component of any control or intervention program, as indicated by various epidemiological surveys. For example, nearly one-half $(44.7 \%)$ of the patients described in a cross-sectional study conducted at a referral service in São Luis, MA, were contacts (Correa et al. 2012). In addition, the presence of antibodies against PGL-I in contacts was associated with a relative risk factor of six times that of negative contacts in Uberlândia (Goulart et al. 2008). An examination of serum samples collected from patient contacts in the Philippines also indicated that elevated or rising antibody levels against PGL-I and LID-1, a chimeric fusion protein comprising ML2331 and ML0405, were predictive of the clinical onset of leprosy (Douglas et al. 2004, Duthie et al. 2007). The time benefit over clinical diagnosis provided by recognising elevated anti-LID-1 IgG levels was estimated to be approximately nine months (Fig. 1A). Real-time confirmation of these findings, through the treatment (or not) of individuals with elevated responses, could represent a major breakthrough within leprosy control programs.

PB patients with low bacterial burdens are not readily detected by antibody responses, which suggest that, in addition to serological tests, a sensitive and specific $\mathrm{T}$ cell diagnostic test would be useful. Detection of a cellmediated response against Mycobacterium tuberculosis $(M t b)$ antigens is the preferred evidence for diagnosis of tuberculosis, either through intradermal injection of purified protein derivative testing or more recently, by ex vivo recall (QuantiFERON tests, Cellestis, Melbourne, Australia) (Mazurek \& Villarino 2003, Connell et al. 2006). We and others have identified various $M$. leprae antigens that elicit interferon (IFN) $\gamma$ secretion from T-cells of tuberculoid leprosy patients, but do not cross react with cells from individuals exposed to BCG or Mtb (Spencer et al. 2005, Duthie et al. 2008, Geluk et al. 2008, 2011, Sampaio et al. 2011a, b). The majority of healthy household contacts (HHC) of MB patients respond in a manner quantitatively and qualitatively comparable to PB patients; however, this is likely indicative of exposure or asymptomatic infection and is a poor diagnostic method for PB disease. Recently, we observed that these same antigens promote interleukin (IL)- 4 or IL-5 secretion in whole blood assays using lepromatous patient blood. Furthermore, we identified an HHC who responded similarly to MB patients (Sampaio et al. 2011a) (Fig. 1C), although it remains unclear whether this individual is developing clinical signs. In addition, evaluation of additional contacts has the potential to reveal antigen-specific responses that can serve as early predictors of disease progression.
Stage 2 - Intervention - Previous chemoprevention strategies - Hailed by Science magazine as the "breakthrough of the year" (Cohen 2011), the concept of preventive chemotherapy for human immunodeficiency virus has followed in the footsteps of years of similar approaches for leprosy. Various chemoprophylaxis trials have been conducted to determine whether pre-emptive "treatment" can interrupt leprosy transmission and reduce disease prevalence. These studies have demonstrated a significant benefit to treating non-diseased individuals, although each has reported a different magnitude and length of protection (Daulako 1999, Tin 1999, Diletto et al. 2000, Nguyen et al. 2000, Smith \& Smith 2000, Vijayakumaran et al. 2000, Moet et al. 2004, Bakker et al. 2005, Smith 2008). The findings of the heralded COLEP trial, which was conducted on approximately 20,000 contacts of new cases in north-west Bangladesh, showed a protective effect associated with single-dose rifampicin (RIF) treatment of $57 \%$ in household and other contacts (Moet et al. 2008a). An earlier Indonesian study found that RIF treatment had a significant effect in communities where all individuals were provided prophylaxis, but no effect in communities where only household contacts and direct neighbours were provided RIF prophylaxis (Bakker et al. 2005, Moet et al. 2008b). These findings were consistent with dapsone prophylaxis programs, which were also more effective when given as a blanket treatment to affected communities (Smith \& Smith 2000). One suggested reason for the relative failure of this approach in contacts of MB patients (physical and related) or seropositive contacts is that by the time the chemoprophylaxis is given, their bacillary load may be too high to be eliminated by a single dose (or as in Indonesia, 2 doses) of RIF.

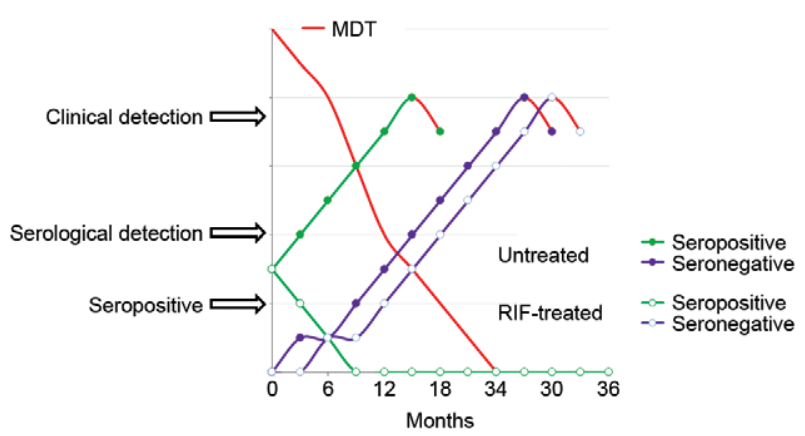

Fig. 2: prediction of the impact of chemoprophylaxis on leprosy development. Various thresholds are plotted on the y-axis; weak seropositivity (serodetection) progressing to elevated seropositivity (permitting serodiagnosis) and subsequently the emergence of skin lesions and neurological damage (permitting clinical diagnosis), against time on the x-axis. As seropositive individuals are at an increased risk of developing leprosy, in a no-treatment scenario, the expectation is that patients will emerge from this group in advance of individuals who are seronegative. In the scenario where chemoprophylaxis is provided, seropositive individuals will effectively be given post-exposure prophylaxis (treatment before the emergence of symptoms) and will not progress, but a minimal affect will be made on the seronegative population. If serodiagnosis is the only additional parameter provided, disease progression could be prevented by the prompt provision of rifampicin (RIF) or multi-drug therapy (MDT). 
Thus, a more extensive chemoprophylaxis regimen may be needed for those at highest risk. The major restriction of chemoprophylaxis, however, is that drugs can only provide protection in individuals already harbouring M. leprae; those infected after the chemoprophylaxis is given have no protection. This restriction is clearly seen in practice, as new case detection rates return to pre-trial levels over a relatively short period of time (Fig. 2). An additional and, in our opinion, more ideal strategy would be to induce a potent and elongated immune response in these individuals that could control and limit the infection long after the treatment period.

Previous immunisation strategies - The principles of prophylactic immunisation may be applied in pre or post-exposure settings, with the aim of preventing infection, disease progression or both. Several attempts have been made to develop a vaccine specifically for leprosy but, at present, BCG is the only vaccine administered for the prevention of leprosy (reviewed in Duthie et al. 2011a). It is noteworthy, however, that leprosy remains prevalent in countries with widespread BCG vaccination programs and, as is the case for TB, protection afforded by $\mathrm{BCG}$ vaccination against leprosy appears to wane over time. Regardless, systematic meta-analyses indicate that BCG vaccination has a protective efficacy of approximately 50\% (Setia et al. 2006, Merle et al. 2010). In addition, protection appears to be better against the MB than PB forms. However, although experimental studies demonstrated a protective effect of $31 \%$ for indeterminate leprosy, observational studies showed an increased risk (Setia et al. 2006) and this difference was likely related to the increased numbers of cases found during active case detection vs. previous periods of passive case detection. Computer modelling based on the 2003 leprosy status in the districts of Nilphamari and Rangpur, Bangladesh, indicated that leprosy incidence would be substantially reduced by effective BCG vaccine coverage of infants and the combined strategies of contact tracing, early diagnosis and treatment of infection and/or chemoprophylaxis among HHC (Fischer et al. 2011). Models including a second BCG vaccination were not generated and the efficacy of this approach has been debated (Setia et al. 2006, Cunha et al. 2008, Duppre et al. 2008, van Brakel et al. 2010).

Moreover, significant efforts are ongoing to improve vaccination against $\mathrm{TB}$ (either through modifications to the $\mathrm{BCG}$ vaccine or development of an entirely new vaccine), although alterations to TB vaccine strategies could potentially be deleterious for leprosy control (Richardus et al. 2011). We consider it unlikely, however, that the current BCG regimen will be supplanted in the foreseeable future. The best vaccination strategy appears to be the development of a vaccine that could be used in addition to, or instead of, the BCG vaccine.

Our intervention strategy - Drug treatment and immunisation - Stage 2 of our program will integrate preventative strategies with active case finding measures. As in previous chemoprevention schemes, we propose to administer a single RIF treatment to cohorts of atrisk individuals (HHC) in highly endemic regions at the time of study intake (Fig. 3). An important question is whether LID-1 can identify contacts whose incubation of $M$. leprae is too advanced to be stopped by singledose RIF treatment and the answer to this question could lead to the recommendation that contacts who are LID-1 seropositive be treated with a full course of MDT.

It is estimated that chemoprophylaxis alone provides a two-year protective window, but it is believed that effective immunisation would provide a much broader protective window. Thus, adapting control strategies to provide both chemoprophylaxis for immediate and short-term protection, along with immunisation to provide longer-term protection, have distinct appeal. Given the anti-mycobacterial properties of RIF and MDT, the BCG vaccine cannot, however, be administered at the same time as any other chemoprophylaxis or therapy. Conversely, immunisation with a defined sub-unit vaccine could be implemented on days 0 and 30 of drug treatment to allow for a short course of chemotherapy (e.g., 30 days) in infected individuals, in addition to providing a secondary layer of protection (Fig. 3).

\section{DISCUSSION}

Measuring the efficacy of interventions - Previous intervention studies have used leprosy incidence as an endpoint to determine efficacy. Although this is the obvious goal of any intervention, given both the relatively low incidence rates even in hyper-endemic regions and the slow development of the disease, this strategy poses logistical problems in that it necessitates the inclusion of large numbers of people and monitoring over long periods of time. While our over-arching strategy is similar to previous efforts [examine person-to-person transmission and associated risk factors (i.e., the proximity and

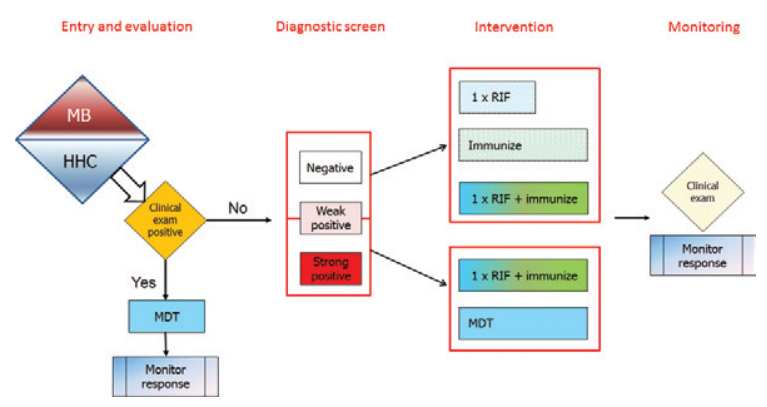

Fig. 3: flow chart of major activities and critical groups in the proposed Infectious Disease Research Institute/American Leprosy Missions intervention program. Healthy household contacts (HHC) would undergo clinical exam at entry and would be evaluated by diagnostic tests. Those with negative results, as well as a subset of individuals with weak results would be selected to receive either single-dose rifampicin (RIF), immunization or RIF in combination with immunization. Those with strong positive results, as well as a subset of individuals with weak results, would be selected to receive either single-dose RIF in combination with immunization or multi-drug therapy (MDT). Responses of these groups would be tracked over time and clinical exams would be performed at regular intervals. This structure will permit the determination of diagnostic capacity of tests, prognostic utility of tests and efficacy of post-exposure intervention(s). MB: multibacillary. 
contact-relationships of known leprosy patients with new leprosy cases), determine the impact of chemoprophylaxis (i.e., measure incidence rates within treated and untreated populations) and determine the additional impact of vaccination (i.e., measure incidence rates within treated and untreated populations)], we aim to further include the validation of tools that can simplify and expedite intervention trials.

At a time when primary prevention of $M$. leprae infection is lacking, the application of immunological and molecular markers that can be used by public health workers to investigate predictive factors of infection and illness is highly pertinent. We believe that we now have the appropriate tools with which to rapidly and objectively assess any interventions, thus limiting the need to wait until the appearance of fulminant leprosy. The findings of localised projects, such as that described in the accompanying article by Rada et al. (2012) that outlines the annual monitoring of leprosy in Mamaria Village and the early identification of patients using simple serological assays, indicate an operational utility that could be implemented on a larger scale.

The immunological responses of those enrolled in our studies will be monitored to assess the effects of preventative drug treatment and vaccination on M. leprae antigenspecific responses. Antigen-specific antibody responses are known to correlate with bacterial burdens and MB patients can be readily detected using serologic assays. In leprosy-endemic regions, significantly more individuals are expected to be seropositive, indicating subclinical infection, than those who actually develop the disease. This is a reasonable assumption given that substantial proportions of individuals in leprosy-endemic regions have antibody responses to PGL-I and that there are reports of individuals who have self-cured. Indeed, the accompanying article by Mariane Stefani's group (Hungria et al. 2012) indicates that a slightly increased proportion of HHC are seropositive to M. leprae antigens in comparison to endemic controls. Seropositive but asymptomatic individuals may either (i) clear the infection, (ii) contain the infection at consistent levels or (iii) propagate $M$. leprae and ultimately produce clinical signs of leprosy. This seropositive but asymptomatic group is perhaps the most interesting to analyse from the viewpoint of reducing infectious reservoirs and the transmission cycle, but has been largely included only serendipitously in prior studies by virtue of being enriched for HHC (i.e., more HHC are seropositive than the general population, although they have typically been included in studies because they are contacts and not because they are seropositive). Although antibody responses in asymptomatic individuals will likely be lower than in patients with high $M$. leprae burdens, elevated antibody responses appear to indicate an increased risk of developing leprosy, particularly with responses that increase over time (Douglas et al. 2004, Duthie et al. 2007) (Fig. 1A). Our data indicate that antibody responses in patients decline during MDT (Duthie et al. 2011b) and we predict that responses in seropositive but asymptomatic individuals will similarly decline upon effective intervention. We are currently examining the effects of treatment on antigen-specific cellular responses to determine if qualitative changes occur and if they could be used as biomarkers to indicate disruption of leprosy.

Centred on simplified and objective screening, our program will facilitate earlier treatment of leprosy patients and intervention in asymptomatic individuals. By establishing easy-to-use diagnostic tests (lab-based and RDT) and read-outs of treatment/intervention efficacy, the outlined studies will provide validated markers that can be used in additional intervention campaigns targeting leprosy-endemic sites. Earlier treatment with drugs will lead to the immediate interruption of infection in the majority of asymptomatic individuals and reduce the potential person-to-person transmission of M. leprae, while immunisation will provide an improved response to treatment and a long-term control measure.

\section{ACKNOWLEDGEMENTS}

To Dr Sharon Busby, for critical reading of the paper.

\section{REFERENCES}

Anderson H, Stryjewska B, Boyanton BL, Schwartz MR 2007. Hansen disease in the United States in the 21st century: a review of the literature. Arch Pathol Lab Med 131: 982-986.

Bakker MI, Hatta M, Kwenang A, Van Benthem BH, Van Beers SM, Klatser PR, Oskam L 2005. Prevention of leprosy using rifampicin as chemoprophylaxis. Am J Trop Med Hyg 72: 443-448.

Bührer-Sékula S, Illarramendi X, Teles RB, Penna ML, Nery JA, Sales AM, Oskam L, Sampaio EP, Sarno EN 2009. The additional benefit of the ML-Flow test to classify leprosy patients. Acta tropica 111: 172-176.

Bührer-Sékula S, Smits HL, Gussenhoven GC, van Leeuwen J, Amador S, Fujiwara T, Klatser PR, Oskam L 2003. Simple and fast lateral flow test for classification of leprosy patients and identification of contacts with high risk of developing leprosy. J Clin Microbiol 41: 1991-1995.

Buhrer SS, Smits HL, Gussenhoven GC, van Ingen CW, Klatser PR 1998. A simple dipstick assay for the detection of antibodies to phenolic glycolipid-I of Mycobacterium leprae. Am J Trop Med Hyg 58: 133-136.

Cho SN, Yanagihara DL, Hunter SW, Gelber RH, Brennan PJ 1983. Serological specificity of phenolic glycolipid I from Mycobacterium leprae and use in serodiagnosis of leprosy. Infect Immun 41: 1077-1083.

Cohen J 2011. Breakthrough of the year. HIV treatment as prevention. Science 334: 1628.

Connell TG, Rangaka MX, Curtis N, Wilkinson RJ 2006. QuantiFERON-TB Gold: state of the art for the diagnosis of tuberculosis infection? Expert Rev Mol Diagn 6: 663-677.

Contin LA, Alves CJ, Fogagnolo L, Nassif PW, Barreto JA, Lauris JR, Nogueira ME 2011. Use of the ML-Flow test as a tool in classifying and treating leprosy. An bras Dermatol 86: 91-95.

Correa R da G, Aquino DM, Caldas Ade J, Amaral DK, Franca FS, Mesquita ER 2012. Epidemiological, clinical and operational aspects of leprosy patients assisted at a referral service in the state of Maranhão, Brazil. Rev Soc Bras Med Trop 45: 89-94.

Croft RP, Nicholls PG, Steyerberg EW, Richardus JH, Cairns W, Smith S 2000. A clinical prediction rule for nerve-function impairment in leprosy patients. Lancet 355: 1603-1606.

Cunha SS, Alexander N, Barreto ML, Pereira ES, Dourado I, de Fatima Maroja M, Ichihara Y, Brito S, Pereira S, Rodrigues LC 2008. BCG 
revaccination does not protect against leprosy in the Brazilian Amazon: a cluster randomised trial. PLoS Negl Trop Dis 2: e167.

Daulako EC 1999. Population screening and mass chemoprophylaxis in Kiribati. Int J Lepr Other Mycobact Dis 67 (Suppl.): S23-S25.

Diletto C, Blanc L, Levy L 2000. Leprosy chemoprophylaxis in Micronesia. Lepr Rev 71 (Suppl.) S21-S23.

Douglas JT, Cellona RV, Fajardo Jr TT, Abalos RM, Balagon MV, Klatser PR 2004. Prospective study of serological conversion as a risk factor for development of leprosy among household contacts. Clin Diagn Lab Immunol 11: 897-900.

Duppre NC, Camacho LA, da Cunha SS, Struchiner CJ, Sales AM, Nery JA, Sarno EN 2008. Effectiveness of BCG vaccination among leprosy contacts: a cohort study. Trans $R$ Soc Trop Med Hyg 102: 631-638.

Duthie MS, Gillis TP, Reed SG 2011a. Advances and hurdles on the way toward a leprosy vaccine. Hum Vaccines 7: 1172-1183.

Duthie MS, Goto W, Ireton GC, Reece ST, Cardoso LP, Martelli CM, Stefani MM, Nakatani M, de Jesus RC, Netto EM, Balagon MV, Tan E, Gelber RH, Maeda Y, Makino M, Hoft D, Reed SG 2007. Use of protein antigens for early serological diagnosis of leprosy. Clin Vaccine Immunol 14: 1400-1408.

Duthie MS, Goto W, Ireton GC, Reece ST, Sampaio LH, Grassi AB, Sousa AL, Martelli CM, Stefani MM, Reed SG 2008. Antigenspecific T-cell responses of leprosy patients. Clin Vaccine Immunol 15: 1659-1665.

Duthie MS, Hay MN, Rada EM, Convit J, Ito L, Oyafuso LK, Manini MI, Goulart IM, Lobato J, Goulart LR, Carter D, Reed SG 2011b. Specific IgG antibody responses may be used to monitor leprosy treatment efficacy and as recurrence prognostic markers. Eur $J$ Clin Microbiol Infect Dis 30: 1257-1265.

Fischer EA, de Vlas SJ, Habbema JD, Richardus JH 2011. The longterm effect of current and new interventions on the new case detection of leprosy: a modeling study. PLoS Negl Trop Dis 5: e1330.

Flower C, Gaskin D, Marquez S 2007. A case of recurrent rash and leg numbness mimicking systemic rheumatic disease: the occurrence of leprosy in a nonendemic area. J Clin Rheumatol 13: 143-145.

Geluk A, Duthie MS, Spencer JS 2011. Postgenomic Mycobacterium leprae antigens for cellular and serological diagnosis of M. leprae exposure, infection and leprosy disease. Leprosy Rev 82: 402-421.

Geluk A, van der Ploeg J, Teles RO, Franken KL, Prins C, Drijfhout JW, Sarno EN, Sampaio EP, Ottenhoff TH 2008. Rational combination of peptides derived from different $M$. leprae proteins improves sensitivity for immunodiagnosis of $M$. leprae infection. Clin Vaccine Immunol 15: 522-533.

Goulart IM, Bernardes Souza DO, Marques CR, Pimenta VL, Goncalves MA, Goulart LR 2008. Risk and protective factors for leprosy development determined by epidemiological surveillance of household contacts. Clin Vaccine Immunol 15: 101-105.

Hungria E, Oliveira R, Sousa AL, Costa MB, Brito de Souza V, Moreno F, Nogueira M, Costa M, Silva S, Bührer-Sékula S, Reed SG, Duthie MS, Silva E, Stefani MM 2012. Seroreactivity to new Mycobacterium leprae protein antigens in different leprosy endemic regions in Brazil. Mem Inst Oswaldo Cruz: 104-111.

Lockwood DN 2002. Leprosy elimination - a virtual phenomenon or a reality? BMJ 324: 1516-1518.

Lockwood DN, Reid AJ 2001. The diagnosis of leprosy is delayed in the United Kingdom. Qjm 94: 207-212.

Lockwood DN, Suneetha S 2005. Leprosy: too complex a disease for a simple elimination paradigm. Bull World Health Organ 83: $230-235$
Mazurek GH, Villarino ME 2003. Guidelines for using the QuantiFERON-TB test for diagnosing latent Mycobacterium tuberculosis infection. Centers for Disease Control and Prevention. MMWR Recomm Rep 52: 15-18.

Meima A, Richardus JH, Habbema JD 2004a. Trends in leprosy case detection worldwide since 1985. Lepr Rev 75: 19-33.

Meima A, Smith WC, van Oortmarssen GJ, Richardus JH, Habbema JD 2004b. The future incidence of leprosy: a scenario analysis. Bull World Health Organ 82: 373-380.

Merle CS, Cunha SS, Rodrigues LC 2010. BCG vaccination and leprosy protection: review of current evidence and status of BCG in leprosy control. Expert Rev Vaccines 9: 209-222.

Moet FJ, Oskam L, Faber R, Pahan D, Richardus JH 2004. A study on transmission and a trial of chemoprophylaxis in contacts of leprosy patients: design, methodology and recruitment findings of COLEP. Lepr Rev 75: 376-388.

Moet FJ, Pahan D, Oskam L, Richardus JH 2008a. Effectiveness of single dose rifampicin in preventing leprosy in close contacts of patients with newly diagnosed leprosy: cluster randomised controlled trial. BMJ 336: 761-764.

Moet FJ, Schuring RP, Pahan D, Oskam L, Richardus JH 2008b. The prevalence of previously undiagnosed leprosy in the general population of northwest bangladesh. PLoS Negl Trop Dis 2: e198.

Nguyen LN, Cartel JL, Grosset JH 2000. Chemoprophylaxis of leprosy in the southern Marquesas with a single $25 \mathrm{mg} / \mathrm{kg}$ dose of rifampicin. Results after 10 years. Lepr Rev 71 (Suppl.) S33-S35.

Nicholls PG, Croft RP, Richardus JH, Withington SG, Smith WC 2003. Delay in presentation, an indicator for nerve function status at registration and for treatment outcome - the experience of the Bangladesh Acute Nerve Damage Study cohort. Lepr Rev 74: 349-356.

Oskam L, Slim E, Bührer-Sékula S 2003. Serology: recent developments, strengths, limitations and prospects: a state of the art overview. Lepr Rev 74: 196-205.

Pandey A, Rathod H 2010. Integration of leprosy into GHS in India: a follow up study (2006-2007). Lepr Rev 81: 306-317.

Pannikar V 2009. Enhanced global strategy for further reducing the disease burden due to leprosy: 2011-2015. Lepr Rev 80: 353-354.

Penna ML, de Oliveira ML, Penna GO 2009. The epidemiological behaviour of leprosy in Brazil. Lepr Rev 80: 332-344.

Rada E, Duthie MS, Reed SG, Aranzazu N, Convit J 2012. Serologic follow-up of $\mathrm{IgG}$ responses against recombinant mycobacterial proteins ML0405, ML2331 and LID-1 in a leprosy hyperendemic area of Venezuela. Mem Inst Oswaldo Cruz: 90-94.

Richardus JH, Saunderson P, Smith C 2011. Will new tuberculosis vaccines provide protection against leprosy? Int J Tuberc Lung Dis 15: 143.

Roche PW, Britton WJ, Failbus SS, Williams D, Pradhan HM, Theuvenet WJ 1990. Operational value of serological measurements in multibacillary leprosy patients: clinical and bacteriological correlates of antibody responses. Int J Lepr Other Mycobact Dis 58: $480-490$

Roche PW, Failbus SS, Britton WJ, Cole R 1999. Rapid method for diagnosis of leprosy by measurements of antibodies to the $M$. leprae 35-kDa protein: comparison with PGL-I antibodies detected by ELISA and "dipstick" methods. Int J Lepr Other Mycobact Dis 67: 279-286.

Sampaio LH, Sousa AL, Barcelos MC, Reed SG, Stefani MM, Duthie MS 2011a. Evaluation of various cytokines elicited during antigenspecific recall as potential risk indicators for the differential development of leprosy. Eur J Clin Microbiol Infect Dis 31: 1443-1451. 
Sampaio LH, Stefani MM, Oliveira RM, Sousa AL, Ireton GC, Reed SG, Duthie MS 2011b. Immunologically reactive M. leprae antigens with relevance to diagnosis and vaccine development. $B M C$ Infect Dis 11: 26.

Setia MS, Steinmaus C, Ho CS, Rutherford GW 2006. The role of BCG in prevention of leprosy: a meta-analysis. Lancet Infect Dis 6: $162-170$.

Shen J, Zhou M, Xu X, Ray A, Zhang G, Yan L 2010. A big challenge in case finding at low endemic situation: analysis on 1,462 new leprosy patients detected in China in 2007. Lepr Rev 81: 176-183.

Siddiqui MR, Velidi NR, Pati S, Rath N, Kanungo AK, Bhanjadeo AK, Rao BB, Ojha BM, Krishna Moorthy K, Soutar D, Porter JD, Ranganadha Rao PV 2009. Integration of leprosy elimination into primary health care in Orissa, India. PLoS ONE 4: e8351.

Smith CM, Smith WC 2000. Chemoprophylaxis is effective in the prevention of leprosy in endemic countries: a systematic review and meta-analysis. MILEP2 Study Group. Mucosal immunology of leprosy. J Infect 41: 137-142.

Smith WC 2008. Chemoprophylaxis in the prevention of leprosy. BMJ 336: 730-731.

Spencer JS, Dockrell HM, Kim HJ, Marques MA, Williams DL, Martins MV, Martins ML, Lima MC, Sarno EN, Pereira GM, Matos H, Fonseca LS, Sampaio EP, Ottenhoff TH, Geluk A, Cho SN, Stoker NG, Cole ST, Brennan PJ, Pessolani MC 2005. Identification of specific proteins and peptides in Mycobacterium leprae suitable for the selective diagnosis of leprosy. J Immunol 175: 7930-7938.
Tin K 1999. Population screening and chemoprophylaxis for household contacts of leprosy patients in the Republic of the Marshall Islands. Int J Lepr Other Mycobact Dis 67: S26-S29.

van Brakel W, Cross H, Declercq E, Deepak S, Lockwood D, Saunderson P, Smith WC, Batty J, Nahodilova L, Soutar D, Augustine V, Ebenso B 2010. Review of leprosy research evidence (20022009 ) and implications for current policy and practice. Lepr Rev 81: 228-275.

Van Buynder P, Eccleston J, Leese J, Lockwood DN 1999. Leprosy in England and Wales. Commun Dis Public Health 2: 119-121.

Vijayakumaran P, Krishnamurthy P, Rao P, Declerq E 2000. Chemoprophylaxis against leprosy: expectations and methodology of a trial. Lepr Rev 71 (Suppl.): S37-S40.

WHO - World Health Organization 1988. WHO Expert Committee on Leprosy. World Health Organ Tech Rep Ser 874: 1-43.

WHO - World Health Organization 2005. Global leprosy situation, 2005. Wkly Epidemiol Rec 80: 289-295.

WHO - World Health Organization 2007. Global leprosy situation, 2007. Wkly Epidemiol Rec 82: 225-232.

WHO - World Health Organization 2010. Global leprosy situation, 2010. Wkly Epidemiol Rec 85: 337-348.

Young DB, Buchanan TM 1983. A serological test for leprosy with a glycolipid specific for Mycobacterium leprae. Science 221: 1057-1059. 